\title{
Electrophysiological Effects of Diphenylhydantoin in Patients with Sinus Node Dysfunction
}

\author{
Yukiko Tsuchioka, M.D., Kaoru Yamaoka, M.D., \\ Masaki Hashimoto, M.D., Masaharu Yamamoto, M.D., \\ Takashi Sueda, M.D., Hideo Matsuura, M.D., \\ Hiroyuki Kurogane, M.D., Goro Kajiyama, M.D., \\ Hironobu TAteishi, M.D.,* Hikaru SATo, M.D., * \\ and Hiroki Mrtsuda, M.D.**
}

\section{SUMmary}

The electrophysiological effects of intravenous administration of diphenylhydantoin (DPH) $(5 \mathrm{mg} / \mathrm{Kg}$, maximum $250 \mathrm{mg}$ ) were studied in 20 patients with sinus node dysfunction (SND). DPH shortened spontaneous cycle length (SCL) in 3 patients and lengthened it in 3. Maximum corrected sinus node recovery time (max CSRT) was prolonged in 7 patients and shortened in 3 . Estimated sinoatrial conduction time was prolonged in 3 patients and shortened in 2 of 10 patients in whom this measurement was possible. However, these changes were not statistically significant. Neither were there any significant changes in $\mathrm{PA}, \mathrm{AH}$ and $\mathrm{HV}$ intervals nor refractory periods of the atrium, the AV node and the ventricle. DPH prolonged SCL and/or max CSRT in 9 of 20 patients with SND, and it was suggested that DPH has depressant effects on the sinus node in some patients with SND. Thus, this drug should be used with caution in the treatment of ventricular arrhythmias accompanied by sinus node dysfunction.

\section{Additional Indexing Words :}

Diphenylhydantoin Sinus node dysfunction Electrophysiological study

$\mathrm{D}$ IPHENYLHYDANTOIN (DPH) has been widely used for the treatment of ventricular arrhythmias. It has been particularly effective in ventricular arrhythmias induced by digitalis toxicity. ${ }^{1), 2)}$ The development of

From the First Department of Internal Medicine, Hiroshima University School of Medicine, Hiroshima, * Internal Medicine, Hiroshima City Hospital, Hiroshima, and ** Internal Medicine, Asa City Hospital, Hiroshima.

Address for reprint: Yukiko Tsuchioka, M.D., First Department of Internal Medicine, Hiroshima University School of Medicine, Kasumi 1-2 3, Minami-ku, Hiroshima 734, Japan.

Received for publication July 4, 1985.

Manuscript revised November 13, 1985. 
sinus arrest in some patients treated with DPH has been reported, ${ }^{3)-5)}$ but there are few reports concerning the effects of DPH on the sinus node and atrium in man.6) The present study was performed to evaluate the electrophysiological effects of the intravenous administration of DPH on the conduction system, particularly the sinus node and atrium in patients with sinus node dysfunction (SND).

\section{Methods}

Patients: 20 patients with SND (average age of $60.4 \pm 10.1,13$ men and 7 women, SND group) and 20 patients without SND (average age of $47.4 \pm 11.3$, 12 men and 8 women, control group) were studied. SND was diagnosed by the presence of one or more of the following abnormalities: 1) persistent sinus bradycardia, 2) documented episodes of sinoatrial block and/or sinus arrest and 3) bradycardia with episodic supraventricular tachyarrhythmias.

Electrophysiological studies: His bundle electrogram (HBE) was recorded using a previously described method." A quadripolar electrode catheter was percutaneously introduced and positioned high in the right atrium. Atrial pacing was performed using the distal 2 poles and a high atrial electrogram was recorded using the proximal 2 poles. A bipolar electrode catheter was positioned at the right ventricular apex for ventricular pacing in 11 patients in the SND group and 15 patients in the control group. Signals from the right atrium and the His bundle were recorded on a Mingograph at a paper speed of $100 \mathrm{~mm} / \mathrm{sec}$ simultaneously with leads II and $V_{1}$ of the electrocardiogram (ECG). HBE was recorded during spontaneous rhythm and atrial and ventricular pacing which were performed by gradually increasing the stimulation rate from 70 to $180 / \mathrm{min}$ in increments of 10 beats $/ \mathrm{min}$. The PA (the interval from the pacing spike to the A wave), $\mathrm{AH}$ and $\mathrm{HV}$ intervals were measured both during spontaneous rhythm and under atrial pacing. Sinus node recovery time (SRT) was defined as the interval from the last paced $\mathbf{P}$ wave to the first spontaneous $\mathbf{P}$ wave which appeared when the pacing was suddenly terminated for 30 or $60 \mathrm{sec}$ at each rate. The corrected SRT (CSRT) was defined as the SRT minus the average sinus cycle length. Maximum SRT (max SRT) and max CSRT were defined as the longest SRT and CSRT recorded in all the trials, respectively. The recovery time was measured with the first spontaneous QRS deflection of the ECG if only junctional escaped beats appeared after pacing. Refractory periods were measured using the atrial and ventricular extra stimulus techniques during atrial and ventricular pacing with various cycle lengths. Atrial and ventricular 
premature beats were delivered with variable coupling intervals after every 8 beats of the basic cycle at twice the diastolic threshold. The sinoatrial conduction time (SACT) was calculated using the following equation: $\mathrm{SACT}=\mathrm{re}-$ turn cycle minus spontaneous sinus cycle / 2 (zone of reset). ${ }^{8}$

The following definitions were used regarding refractory periods ${ }^{9}: S_{1}$, $A_{1}, H_{1}$ and $V_{1}$ represented the stimulus artifact, atrial, His bundle and ventricular electrogram of driven beats, respectively. $\mathrm{S}_{2}, \mathrm{~A}_{2}, \mathrm{H}_{2}$ and $\mathrm{V}_{2}$ represented the stimulus artifact, atrial, His bundle and ventricular electrograms in response to the extra stimulus, respectively. The effective refractory period (ERP) of the atrium was the longest $S_{1}-S_{2}$ interval at which $S_{2}$ did not propagate into the atrium. The functional refractory period (FRP) of the atrium was the shortest attainable propagated $A_{1}-A_{2}$ interval. The ERP of the $\mathrm{AV}$ node was the longest $\mathrm{A}_{1}-\mathrm{A}_{2}$ interval at which $\mathrm{A}_{2}$ failed to depolarize the His bundle. The FRP of the AV node was the shortest $\mathrm{H}_{1}-\mathrm{H}_{2}$ interval in response to any $A_{1}-A_{2}$. The ERP of the ventricle was the longest $S_{1}-S_{2}$ interval at which $S_{2}$ failed to evoke a ventricular response. The FRP of the ventricle was the shortest $V_{1}-V_{2}$ interval as measured on the ECG or local ventricular electrogram in response to any $S_{1}-S_{2}$ interval.

DPH was administered intravenously in a dose of $5 \mathrm{mg} / \mathrm{Kg}$ (maximum $250 \mathrm{mg}$ ) over $10 \mathrm{~min}$, and all the electrophysiologic measurements were repeated $10 \mathrm{~min}$ after the administration.

Statistical analysis of the data was performed using the Wilcoxon rank sign test, and the results were expressed as mean \pm standard error.

\section{RESULTS}

AV junctional rhythm developed in 2 patients in the SND group after DPH. DPH shortened the spontaneous cycle length (SCL) in 3 patients and lengthened it in 5 of 20 paticnts with SND. The changes in mean SCL were not statistically significant in either group (Fig. 1).

In the control group, max CSRT was not significantly prolonged by DPH. In the SND group, max CSRT was shortened to more than 1000 msec in 3 patients, unchanged in 10 and prolonged to more than $1000 \mathrm{msec}$ in 7 after DPH injection : mean max CSRT changed from $2143 \pm 445$ to $2663 \pm$ $546 \mathrm{msec}$ (ns) (Fig. 2). Mean max SRT changed from $1201 \pm 46$ to $1273 \pm 52$ (ns) in the control group and from $3370 \pm 464$ to $3886 \pm 569 \mathrm{msec}$ (ns) in the SND group (Table I).

SACT could be measured in 10 patients with SND and 19 without SND before and after DPH administration. Estimated SACT was shortened in 2 patients and prolonged in 3 with SND. The changes of the SACT were not 


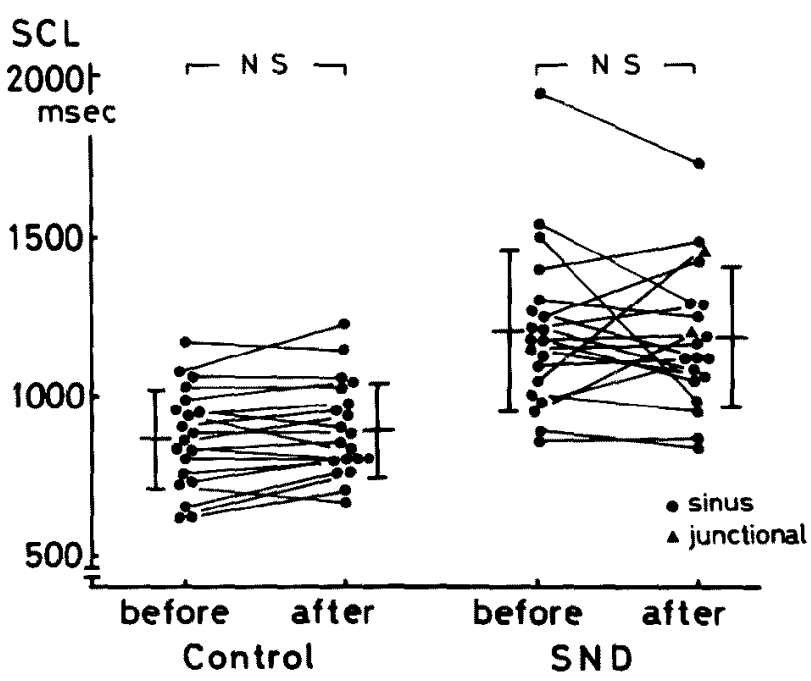

Fig. 1. Sinus cycle length (SCL) before and after diphenylhydantoin in control and sinus node dysfunction (SND) groups. $\quad=$ sinus rhythm; $\Delta=$ junctional escaped rhythm.

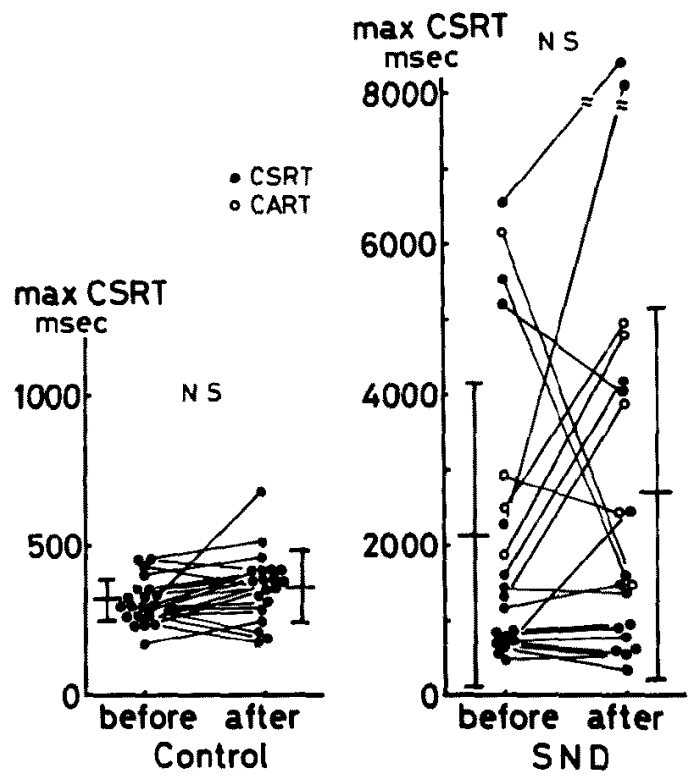

Fig. 2. Maximum corrected sinus node recovery time ( $\max$ CSRT) before and after diphenylhydantoin. $\quad=\max$ CSRT; $O=$ maximum corrected automaticity recovery time. 


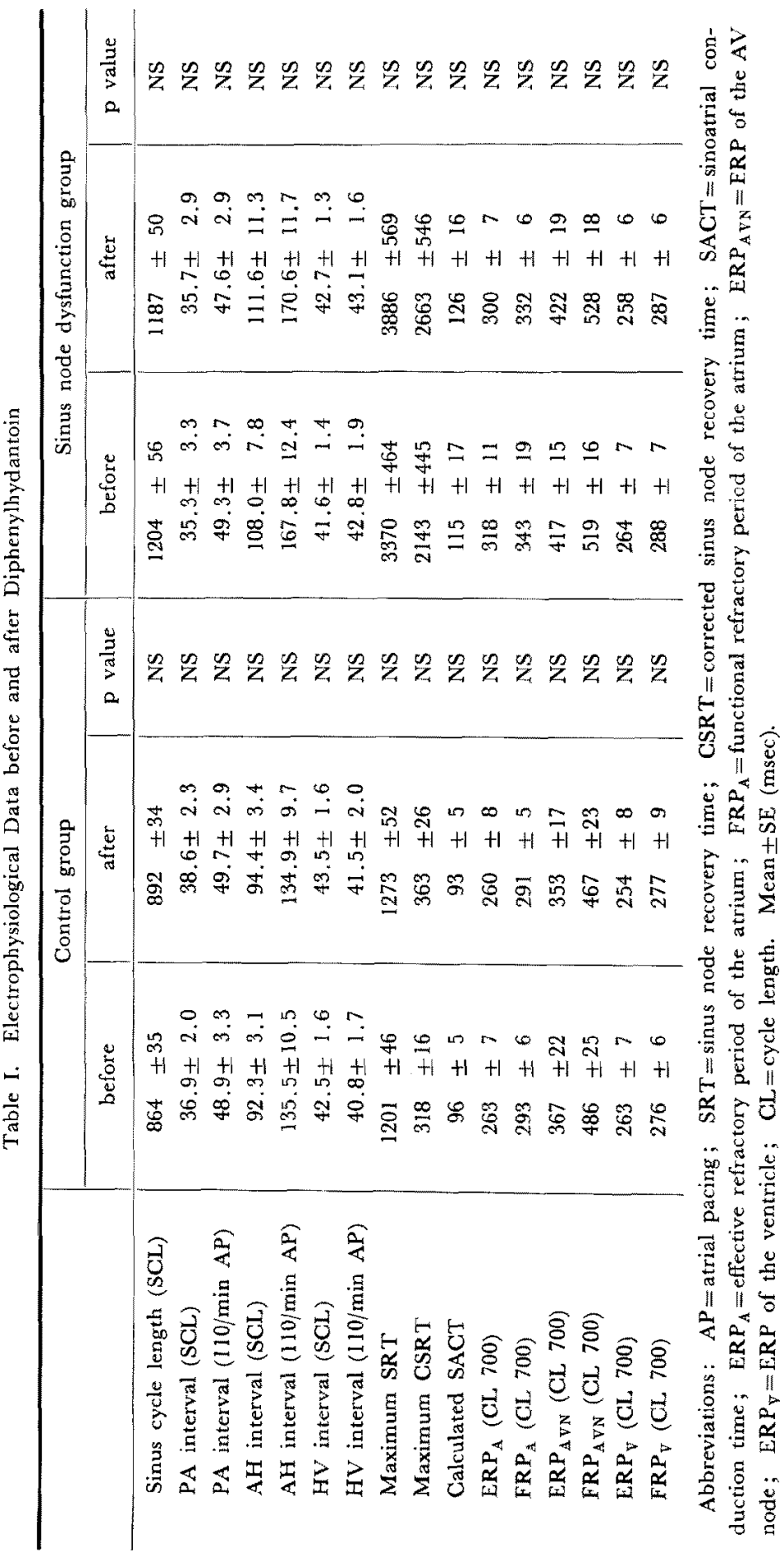




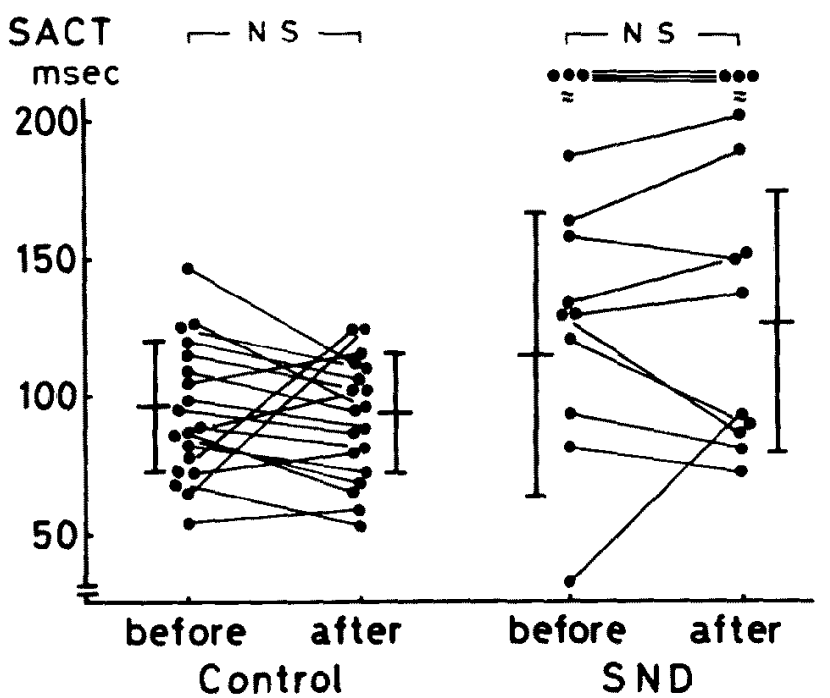

Fig. 3. Sinoatrial conduction time (SACT) before and after diphenylhydantoin in both groups.

significant in either group (Fig. 3).

The changes in the PA, $\mathrm{AH}$ and $\mathrm{HV}$ intervals during sinus rhythm and atrial pacing were not statistically significant in either group (Table I). Refractory periods of the atrium, the AV node and the ventricle were not significantly changed in either group after DPH administration (Table I).

\section{Discussion}

DPH has been widely used for ventricular arrhythmias, as has lidocaine. In experimental studies performed on the Purkinje fiber, DPH decreased action potential amplitude, maximum upstroke velocity of phase 0 , the slope of phase 4 depolarization, action potential duration and membrane responsiveness. ${ }^{10}$ Several cases of severe sinus bradycardia and/or sinus arrest with DPH have been reported. ${ }^{3-51}$ However, the electrophysiological basis of these cases has not been fully elucidated. Since there have been few reports concerning the effects of DPH on the sinus node in man, the electrophysiological studies werc performed to clarify the clinical effects of DPH on the sinus node.

In the present study, DPH had no effect on mean SCL, the PA, AH and HV intervals, refractory periods of the atrium, the AV node and the ventricle, and mean SACT in either group. These observations are in agreement with previous reports, ${ }^{61,11)-13)}$ except for the $\mathrm{AH}$ interval which was reported to be 
shortened. ${ }^{11,121}$

Volkmann et $\mathrm{al}^{6}$ ) showed that the CSRT was prolonged in patients with SND and unchanged in patients without SND after DPH. Ng et al' ${ }^{14}$ showed that the SRT was unchanged by DPH injection in patients administered strophanthin. In the present study, the mean max CSRT was not significantly increased in the control group. In the SND group, the max CSRT was shortened in 3 patients and prolonged in 7, while the mean max CSRT was not significantly affected. The prolongation of the max CSRT may have been caused by the depressant effects of the sinus node automaticity and/or by the sinoatrial exit block. The shortening of the max CSRT may have been caused by depressant effects on the retrograde sinoatrial conduction, because the SACT was prolonged in 2 and the first sinoatrial block remained unchanged in one of the 3 patients in whom $\max$ CSRT was shortened. These effects of DPH on the conduction system in patients with and without SND were nearly similar to those observed with lidocaine. ${ }^{71}$

In our data, the SCL and/or max CSRT was prolonged after DPH in only one of 6 patients in whom SCL and/or max CSRT was markedly prolonged before DPH ( $>1500 \mathrm{msec},>5 \mathrm{sec}$, respectively), but DPH prolonged the SCL and/or max CSRT in 9 of 20 patients in the SND group. It was suggested that DPH has depressant effects on the sinus node in some patients with SND. Thus, DPH should be used with caution in the treatment of ventricular arrhythmias accompanied by sinus node dysfunction.

\section{REFERENCES}

1. Conn RD: Diphenylhydantoin sodium in cardiac arrhythmias. New Engl J Med 272: 277, 1965

2. Lang TW, Bernstein MD, Barbiert F, Gold H, Corday E: Digitalis toxicity: treatment with diphenylhydantoin. Arch Intern Med 116: 573, 1965

3. Wood RA: Sinoatrial arrest: an interaction between Phenytoin and Lignocaine. Br Med J 20: 645,1971

4. Blumsohn D, Ch B, Med D, Seabrook M: Oral diphenylhydantoin sodium and cardiovascular toxicity. S Afr Med J 24: 1207, 1970

5. Rosen M, Lisak R, Rubin IL: Diphenylhydantoin in cardiac arrhythmias. Am J Cardiol 20: 674,1967

6. Volkmann VII, Paliege R: Die Wirkung von Diphenylhydantoin auf Sinusknotenautomatie und sinus-atriale Leitungszeit gei Patienten mit und ohne Sisk-Sinus-Syndrome. Z Ges Inn Med 33: 237, 1978

7. Ishii Y, Mitsuda H, Eno S, Fukui N, Iwamoto T, Fujitani K, Furuta Y, Yoshida M, Miyoshi A, Tateishi $H$, Suzukawa $M$ : Electrophysiological effects of lidocaine in sick sinus syndrome. Jpn Heart J $21: 27,1980$

8. Strauss HC, Saroff AL, Bigger JT Jr, Giardina EGV: Premature atrial stimulation as a key to the understanding of sinoatrial conduction in man. Circulation 47:86, 1973

9. Denes $P, W u ~ D$, Dhingra R, Pietras RJ, Rosen KN: The effect of cycle length on cardiac refractory periods in man. Circulation 49: 32,1974 
10. Bigger JT Jr, Bassett AL, Hoffman BF: Electrophysiological effects of diphenylhydantoin on canine Purkinje fibers. Circ Res 22: 221, 1968

11. Helfant RH, Scherlag BJ, Damato AN: The electrophysiological properties of diphenylhydantoin sodium as compared to procainamide in the normal and digitalis-intoxicated heart. Circulation 36: 108, 1967

12. Caracta AR, Damato AN, Josephson ME, Ricciutti MA, Gallagher JJ, Lau SH: Electrophysiologic properties of diphenylhydantoin. Circulation 47: 1234, 1973

13. Bissett JK, Soyza NDB, Kane JJ, Murphy ML: Improved intraventricular conduction of premature beats after diphenylhydantoin. Am J Cardiol 33: 493, 1974

14. Ng CK, Husslein P, Constantini R, Dienstl F, Simma H, Gmeiner R: Die Wirkung von Strophantin auf die Sinusknoten function und die intrakardiale Erregungsleitung. Z Kardiol 66: 223,1977 